\title{
Leader-Following Control System Design for a Towed Vessel by Tugboat
}

\author{
Tran Duc Quan ${ }^{\circledR *}$, Jin-Ho Suh ${ }^{*}$ and Young-Bok Kim ${ }^{\oplus^{* *}}$ \\ "Department of Mechanical System Engineering, Pukyong National University, Busan, Korea
}

KEY WORDS: Towed vessel, Tugboat, Barge ship, Power propulsion system, Towing vessel, Steering performance, Rudder, Mathematical model

\begin{abstract}
In this study, a motion control problem for the vessels towed by tugboats or towing ships on the sea is considered. The towed vessels, such as barge ships, are used for several purposes. Generally, these vessels have no power propulsion system and are towed using ropes and towing vessel (tugboats). The basic mathematical model of the towed vessel in which three active rudders are attached was introduced from a previous study. Owing to the dependency of the motions of the towed vessel to the towing ship, a method is suggested to cope with the undesirable disturbance and improve the tracking performance. For the simulation study, a model of the towed vessel with a towing ship is made, and necessary physical parameters are identified from the experiment. For the defined and linearized model, a control system is designed, and the control performance is also evaluated. A simulation study is conducted and the effectiveness of the proposed control strategy is verified
\end{abstract}

\section{Introduction}

The development of control and measurement technology has made remarkable results irrespective of its application areas and subjects. Notably, applications to the marine field are increasing and more recently extending to the area where autonomous navigation is possible. Although it is already possible in the aeronautical and land sectors at the commercialization level, the application of advanced technology in the marine industry is still relatively limited due to the harsh ocean environment.

In the early $1990 \mathrm{~s}$, different control technologies were applied in ship motion control problems. The main issue was the problem of path control at a low or constant speed. Therefore, complex and intricate research studies have been conducted. An example is multivariate neural controller design methods for automatic berthing of ships using a multilayer feedforward neural network proposed by Yamato et al. (1990) and Zhang et al. (1997). A thought-provoking research on ship motion control is the construction of a ship with four azimuth type propellers (Fossen, 2002). This study has been evaluated as the most leading research and is being used as a dynamic positioning system (DPS) for floating production storage and offloading (FPSO) and drillship.

In previous studies, the goal was to maintain the right path in the ocean. In other words, the technology capable of performing this control task has been developed using the main propulsion device and the rudder without the side thrusters.

However, more sophisticated ship motion control strategies are necessary when the ship starts to approach the harbor. To partially overcome the stability problem of the berthing process, several solutions have been proposed. In these cases, the ship moves parallel to the seawall with only the side thrusters to complete the final step (Bui et al., 2010).

More advanced studies, including remote control of four tugboats (Bui et al., 2011; Bui and Kim, 2011) and the ship-guiding system with damper and rope (Tran et al., 2014), have been conducted. A berthing support technique is considered to improve the stability of the docking operation at the final stage.

The various ship motion control methods and techniques described above are implemented by installing an active control device on the controlled vessel. In other words, the independent motion control system is equipped on the vessel.

On the sea, it is necessary to use non-powered ships (such as barges) equipped with special devices. As the examples, for moving a large structure from a shipyard to other locations, the barge-type vessels are used and dragged by tugboats. Moreover, cargo vessels without a propulsion system are employed for transporting sand and cargo. In this case, the cargo vessel itself does not have any device to secure the maneuverability. However, it is difficult to match the moving path of the barge with the moving route of the tugboat due to loss of maneuverability. Hence, safe maneuvering may be

Received 17 August 2019, revised 14 October 2019, accepted 16 October 2019

Corresponding author Young-Bok Kim: +82-51-629-6197, kpjiwoo@pknu.ac.kr, ORCID:https://orcid.org/0000-0001-6035-6744

(c) 2019, The Korean Society of Ocean Engineers

This is an open access article distributed under the terms of the creative commons attribution non-commercial license (http://creativecommons.org/licenses/by-nc/3.0) which permits unrestricted non-commercial use, distribution, and reproduction in any medium, provided the original work is properly cited. 


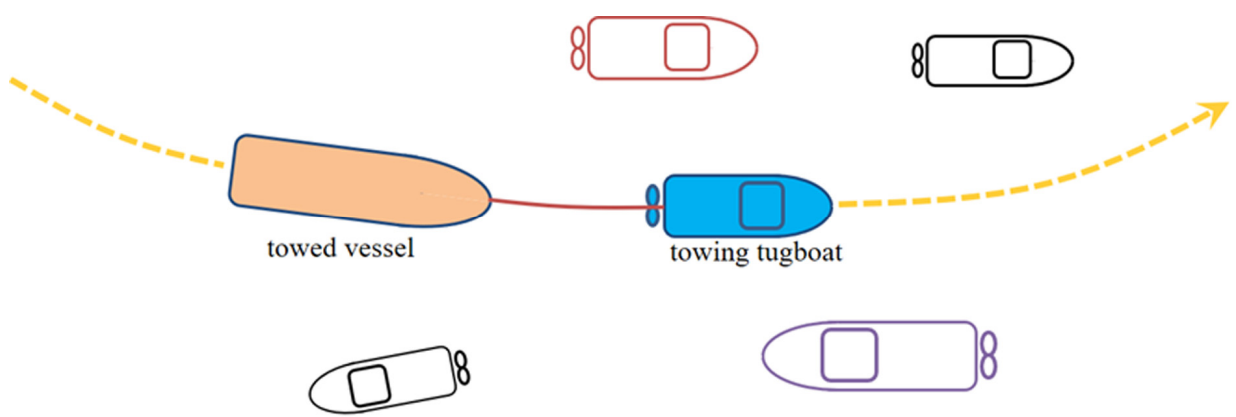

Fig. 1 Description of towed ship motions due to hard and harsh environment constraints

impossible in harsh sea conditions.

As shown in Fig. 1, dangerous problems such as collision accidents may occur due to the wave disturbance and complex maneuvering environment induced by other moving vessels. The possibility of collision with other ships may increase if the towed vessel deviates from the path of the tugboat.

In this study, a method to solve the problems mentioned above is considered. To facilitate the maneuverability of non-powered vessels such as barges and water-wheel-type power generation systems shown in Fig. 2, the authors introduce a novel strategy with a control system designed for the towed and towing vessel system shown in Fig. 2(a) based on a leader-following concept.

The rudders are installed on the vessel to give a minimal function to the powerless towed vessel. Based on this system configuration, a basic model to analyze the system dynamics is derived. Related

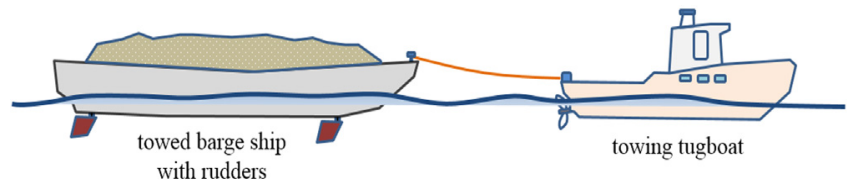

(a) Barge type vessel towed by tugboat
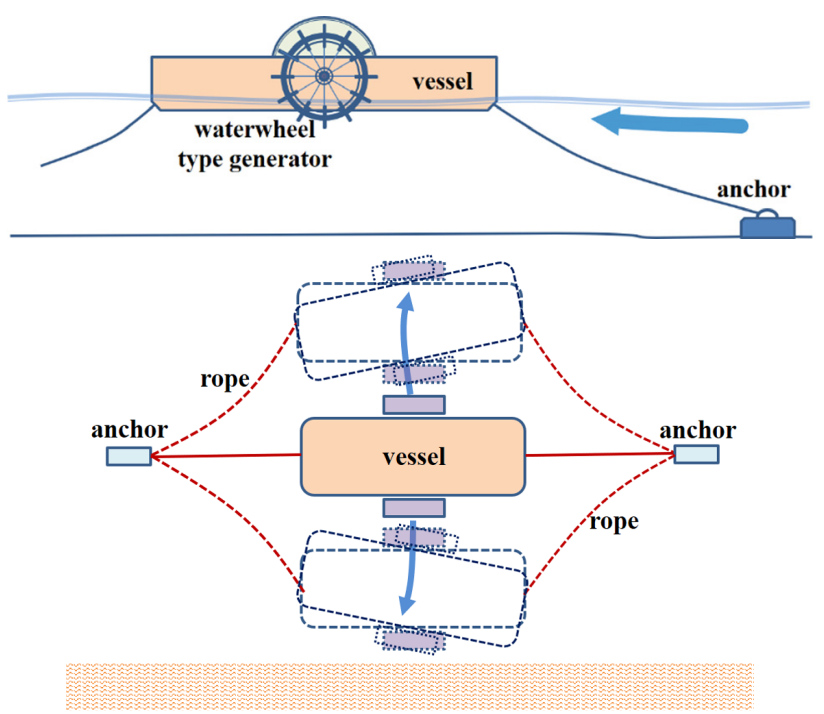

(b) Position control system of floating type power generation system

Fig. 2 Schematics of the controlled system with active rudders studies such as Lee et al. (2000) and Tran and Kim (2016) obtained remarkable results. However, these studies considered only the rope dynamics and physical characteristics without including the system dynamics of the towed vessel.

Therefore, in this study, the authors consider that an appropriate number of rudders are installed on the towed vessel, as illustrated in Fig. 2(a). Consequently, a method to improve the maneuverability of the vessel is discussed. In other words, without a propulsion system, only a rudder control system is introduced to improve the steering performance of the towed vessel. It is possible to operate the rudder system, whether by installing a small power generator, a battery, or a power supply from the towing vessel. Based on the system configuration mentioned above, the authors derive a precise and accurate system model description. The control system is designed, and simulation results are presented to evaluate the control performance.

\section{Modeling of the towed vessel}

As shown in Fig. 2, particular 2(a), the controlled vessel does not have any self-thrust force but is towed by the tugboat using a rope. Here, it is assumed that three rudders are adequately installed at arbitrary positions, as shown in Fig. 3.

However, the system configuration of this study can be extended to the problem of optimizing the rudder numbers, installing them to the position, and other related issues. For example, a control system design problem with single- or multi-rudder system can be considered.

In general, the cargo ships are towed by tugboats to move to the designated position. In this case, the towed cargo ships may not actively use the propulsion system except the rudders. Recently, the vessels are equipped with several azimuth propulsion systems with rudder function.

Moreover, another application target is illustrated in Fig. 2(b). It is a water-wheel-type power generator that is operated on the river by anchoring and controlled by a motion control system with several rudders.

If we consider this fact, there is no doubt about the system configuration of Fig. 3 and the issues discussed in this study.

Based on this fact, the system dynamics are analyzed with the assumption that the three rudders are installed on the towed vessel 


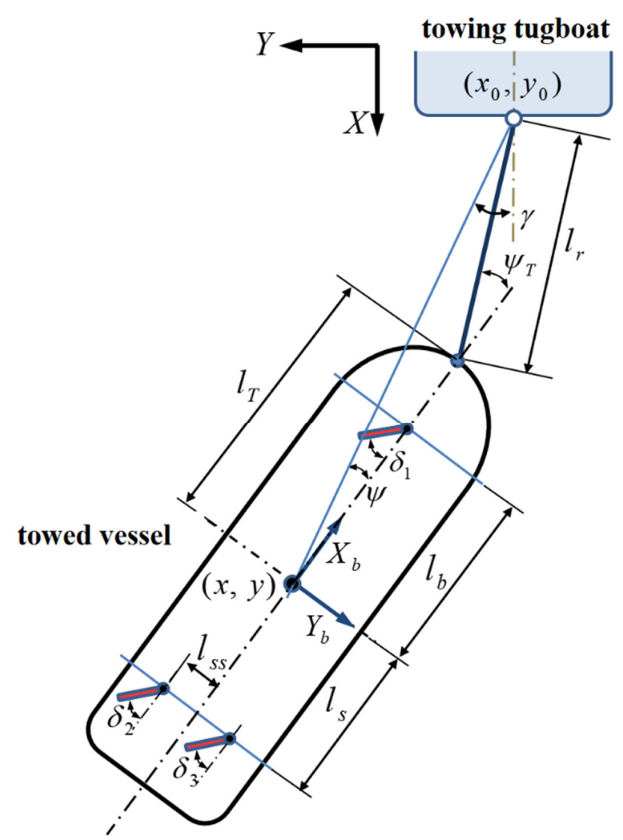

Fig. 3 Controlled vessel description with towing vessel

without propulsion force.

Additionally, it is assumed that the rudder positions are symmetrical in the plane. The weight and the center of rotation are also close to the center of the coordinates. The vessel dynamics are then generally expressed by the following linear model:

$$
\begin{aligned}
& M \dot{v}+D v=\tau \\
& \dot{\eta}=R(\psi) v
\end{aligned}
$$

where $M \in R^{3 \times 3}$ is the inertia matrix and $D\left(v_{r}\right) \in R^{3 \times 3}$ is the damping matrix which are expressed as follows:

$$
M=\left[\begin{array}{ccc}
m-X_{\dot{u}} & 0 & 0 \\
0 & m-Y_{\dot{v}} & -Y_{\dot{r}} \\
0 & -N_{\dot{v}} & I_{z}-N_{\dot{r}}
\end{array}\right], \quad D=\left[\begin{array}{ccc}
-X_{u} & 0 & 0 \\
0 & -Y_{v} & -Y_{r} \\
0 & -N_{v} & -N_{r}
\end{array}\right]
$$

and $\eta=[x, y, \psi]^{T} \in R^{3}$ represents the position $(x, y)$ and the heading angle $\psi$ in the earth-fixed frame. In addition, $v=[u, v, \tau]^{T} \in R^{3}$ describes the surge, sway, and yaw rate of ship motion in the body-fixed frame. Moreover, the rotation matrix $R(\psi)$ in Eq. (1) in heading direction describes the kinematic equation of motion. That is:

$$
R(\psi)=\left[\begin{array}{ccc}
\cos \psi & -\sin \psi & 0 \\
\sin \psi & \cos \psi & 0 \\
0 & 0 & 1
\end{array}\right]
$$

The parameters shown in Eq. 3 are summarized as follows:

$m$ : body mass of the towed vessel

$I_{z}$ : the moment of inertia about the z-axis

$X_{\dot{u}}, Y_{\dot{v}}, Y_{\dot{r}}$ : additional mass

$$
\begin{aligned}
& N_{\dot{v}}, N_{\dot{r}}: \text { the additional moment of inertia } \\
& u, v: x, y \text { direction velocity component }
\end{aligned}
$$

As shown in Fig. 3, we consider that the connecting point at the tugboat is the target of the towed vessel since the leading tugboat tows the controlled vessel with rope. It means that the tracking route is made by the connecting point. The 3 DOF equation of towed vessel motion using polar coordinates connecting points can be solved by introducing the weather optimal positioning control (WOPC) method (Fossen, 2002). The parameters are denoted as follows:

$\left(x_{0}, y_{0}\right)$ : connecting point at the towing vessel

$(x, y)$ : control position (center of the towed vessel)

$\psi:$ towed vessel heading angle

$\psi_{T}$ : towed vessel relative heading angle about the rope center line

$\gamma$ : relative angle made by the target position and the control position

$\delta_{i}(i=1,2,3)$ : rudder rotation angle

$l_{r}:$ length of rope connecting two vessels

$l_{T}$ : distance from the target position to the rope connecting point of the towed vessel

$l_{b}$ : distance from the center of rudder \#1 to the center of gravity of the towed vessel (control position)

$l_{s}$ : distance from the center of rudder \#2, \#3 to the center of gravity of the towed vessel

$l_{s s}$ : distance from the center of rudder \#2, \#3 to the center of gravity of the towed vessel in surge direction

A model of the towed vessel is then expressed as follows:

$$
M_{x} \ddot{x}+D_{x} \dot{x}=T^{-T}(x)\left[q\left(v, x, \dot{p}_{0}, \ddot{p}_{0}\right)+\tau\right]
$$

where

$$
\begin{aligned}
& T(x)=H^{-1}\left(l_{c}\right) R^{T}(\gamma) R(\psi) \\
& M_{x}=T^{-T} M T^{-1}, D_{x}=T^{-T} D T^{-1} \\
& q\left(v, x, \dot{p}_{0}, \ddot{p}_{0}\right)=M R^{T}(\psi) L \ddot{p}_{0}+M \dot{R}^{T}(\psi) L \dot{p}_{0}+D R^{T}(\psi) L \dot{p}_{0}(7) \\
& R(\gamma, \psi)=\left[\begin{array}{ccc}
\cos (\gamma, \psi) & -\sin (\gamma, \psi) & 0 \\
\sin (\gamma, \psi) & \cos (\gamma, \psi) & 0 \\
0 & 0 & 1
\end{array}\right] \approx\left[\begin{array}{ccc}
1 & -\gamma(\psi) & 0 \\
\gamma(\psi) & 1 & 0 \\
0 & 0 & 1
\end{array}\right]
\end{aligned}
$$

(if $\gamma$ is sufficiently small)

$$
H\left(l_{c}\right)=\left[\begin{array}{lll}
1 & 0 & 0 \\
0 & l_{c} & 0 \\
0 & 0 & 0
\end{array}\right], \quad L=\left[\begin{array}{ll}
1 & 0 \\
0 & 1 \\
0 & 0
\end{array}\right]
$$

Based on the description of Eq. (4) - Eq. (8), Tran et al. (2018) established a system representation. By following their result, we 
assume that the speed of the towing vessel is constant $\left(\ddot{p}_{0}=0\right)$. The states for the newly defined (linearized) system are given as follows:

$$
x_{e}=\left\lceil\dot{l}_{c}, \dot{\gamma}, \dot{\psi}, l_{c}, \gamma, x_{0}, y_{0}, \dot{x}_{0}, \dot{y}_{0}, x, y, \psi\right\rceil^{T}
$$

Therefore, the state equation is expressed as follows:

$$
\dot{x}_{e}=A_{e} x_{e}+B_{e} \tau
$$

For convenience, let us classify the states of Eq. (10) as follows:

$$
x_{e}=\left\lceil x_{1}^{T}, x_{2}^{T}, x_{3}^{T}, x_{4}^{T}, x_{5}^{T}\right\rceil^{T}
$$

where the element states are:

$$
x_{1}=\left|\begin{array}{c}
i_{c} \\
\dot{\gamma} \\
\dot{\psi}
\end{array}\right|, x_{2}=\left[\begin{array}{l}
l_{c} \\
\gamma
\end{array}\right], x_{3}=\left[\begin{array}{c}
x_{0} \\
y_{0}
\end{array}\right], x_{4}=\left[\begin{array}{c}
\dot{x}_{0} \\
\dot{y}_{0}
\end{array}\right], x_{5}=\left[\begin{array}{c}
x \\
y \\
\psi
\end{array}\right]
$$

Then, the state of Eq. (10) is represented as follows:

$$
\dot{x}_{e}=\left[\begin{array}{c}
\dot{x}_{1} \\
\dot{x}_{2} \\
\dot{x}_{3} \\
\dot{x}_{4} \\
\dot{x}_{5}
\end{array}\right]=\left[\begin{array}{lllll}
A_{11} & A_{12} & A_{13} & A_{14} & A_{15} \\
A_{21} & A_{22} & A_{23} & A_{24} & A_{25} \\
A_{31} & A_{32} & A_{33} & A_{34} & A_{35} \\
A_{41} & A_{42} & A_{43} & A_{44} & A_{45} \\
A_{51} & A_{52} & A_{53} & A_{54} & A_{55}
\end{array}\right]\left[\begin{array}{c}
x_{1} \\
x_{2} \\
x_{3} \\
x_{4} \\
x_{5}
\end{array}\right]+\left[\begin{array}{c}
B_{e 1} \\
0 \\
0 \\
0 \\
0
\end{array}\right] \tau
$$

where the elements of the matrix in Eq. (13) are given as follows:

$$
\begin{aligned}
& A_{11}=-M_{x}^{-1} D_{x}, A_{12}=\left[0^{3 \times 2}\right], A_{13}=\left[0^{3 \times 2}\right] \\
& A_{14}=M_{x}^{-1} T^{-T}\left\{M \dot{R}^{-T}(\psi)+D R^{T}(\psi) L\right\}, A_{15}=\left[0^{3 \times 3}\right] \\
& A_{21}=\left[\begin{array}{lll}
1 & 0 & 0 \\
0 & 1 & 0
\end{array}\right], A_{22}=A_{23}=A_{24}=A_{25}=\left[0^{2 \times *}\right] \\
& A_{31}=A_{32}=A_{33}=A_{35}=\left[0^{2 \times *}\right], A_{34}=\left[I^{2 \times 2}\right] \\
& A_{41}=A_{42}=A_{43}=A_{44}=A_{45}=\left[0^{2 \times *}\right] \\
& A_{51}=R(\psi) H, A_{52}=\left[0^{3 \times 2}\right] \\
& A_{53}=L, A_{54}=A_{55}=\left[0^{3 \times *}\right] \\
& B_{e 1}=M_{x}^{-1} T^{-T}
\end{aligned}
$$

\section{Control system design}

The control parameters are the position $(x, y)$ and heading angle $\psi$ of the towed vessel.

Based on this definition, the authors designed an optimal control system for tracking the target route and angle.

In this study, the model ship is used as a towed vessel which was employed in a previous study (Bui et al., 2011). This ship model will also be used for the experimental study.

Subsequently, the parameters of the towed vessel represented in Eqs. (1) and (2) are given as follows:

$$
\begin{gathered}
M=\left[\begin{array}{ccc}
22.5[\mathrm{~kg}] & 0 & 0 \\
0 & 41.5[\mathrm{~kg}] & 0.65\left[\mathrm{~kg} \times \mathrm{m}_{2}\right] \\
0 & 0.65[\mathrm{~kg}] & 5.26\left[\mathrm{~kg} \times \mathrm{m}_{2}\right]
\end{array}\right] \\
D=\left[\begin{array}{ccc}
1.74[\mathrm{~kg} / \mathrm{s}] & 0 & 0 \\
0 & 6.7[\mathrm{~kg} / \mathrm{s}] & 0.5[\mathrm{~kg} / \mathrm{s}] \\
0 & 0.5[\mathrm{~kg} / \mathrm{s}] & 1.78[\mathrm{~kg} / \mathrm{s}]
\end{array}\right]
\end{gathered}
$$

We define the rope length and rudder positions illustrated in Fig. 3 and Fig. 4 as:

$$
l_{r}=0.5 \mathrm{~m}, l_{T}=1.0 \mathrm{~m}, l_{b}=0.8 \mathrm{~m}, l_{s}=0.7 \mathrm{~m}, l_{s s}=0.1 \mathrm{~m}
$$

At first, we introduce simulation results of the uncontrolled case. Figure 4 shows the motions of the towing and towed vessels. The dashed line is the moving route and the heading angle of the towing vessel, whereas the solid line indicates the motion of the towed vessel. From the route tracking performance shown in Fig. 4(d), it is clear that the control system should be incorporated into this system to maintain the stability of the tracking route.

The given mathematical model of the controlled system with the towing vessel is expressed in the state-space system from Eq. (10) - Eq. (14). In this study, a control system is designed based on optimal control theory (Chingiz et al., 2015; Ji et al., 2018; Lopez and Rubio, 1992; Wondergem et al., 2011; Zwierzewicz, 1999). Generally, it is critical to obtain the state information directly, such that a full order observer is provided. A full-state observer for the given linear system is provided as follows:

$$
\dot{\hat{x}}_{e}=A_{e} \hat{x}_{e}+B_{e} \tau+L_{k}\left(y-C_{e} \hat{x}_{e}\right)
$$

where $x_{e}$ is the actual state and $\hat{x}_{e}$ is the estimated state. By defining the observer estimation error as $e_{x}=x_{e}-\hat{x}_{e}$, the following relation is obtained.

$$
\begin{aligned}
\dot{e}_{x} & =\dot{x}_{e}-\dot{\hat{x}}_{e}=\left(A_{e}-L_{k} C_{e}\right)\left(x_{e}-\hat{x}_{e}\right)+d w_{d} \\
& =\left(A_{e}-L_{k} C_{e}\right) e_{x}+d w_{d}
\end{aligned}
$$

Based on the servo system configuration with state observer (see Fig. 6), we have:

$$
\begin{aligned}
w_{e} & =r-y \\
& =r-C_{e} x_{e}
\end{aligned}
$$

The state equation (10) with feedback law is represented as follows: 


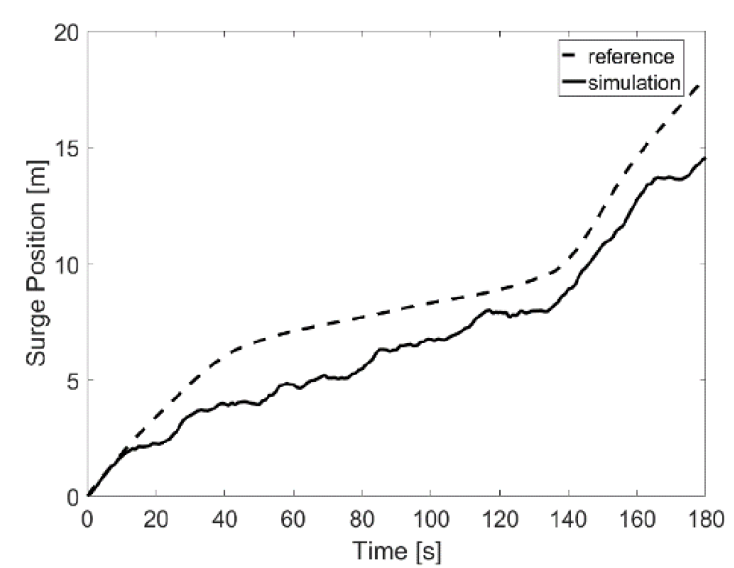

(a) Surge motion

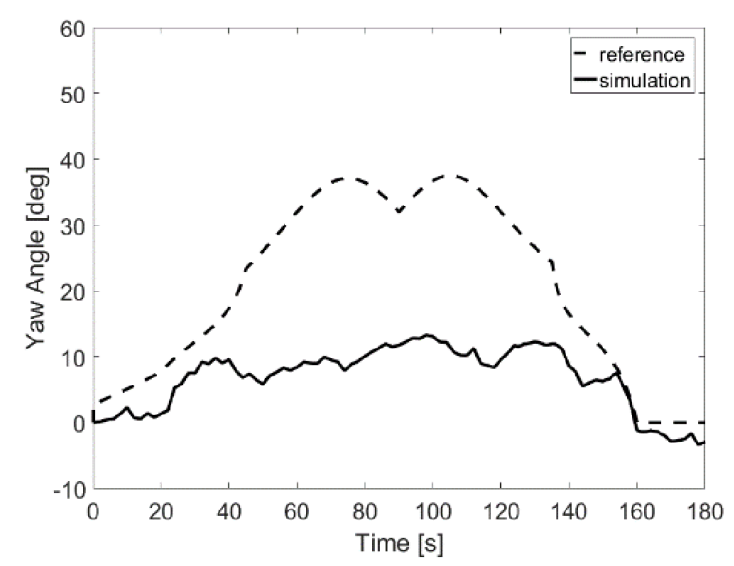

(c) Yaw motion

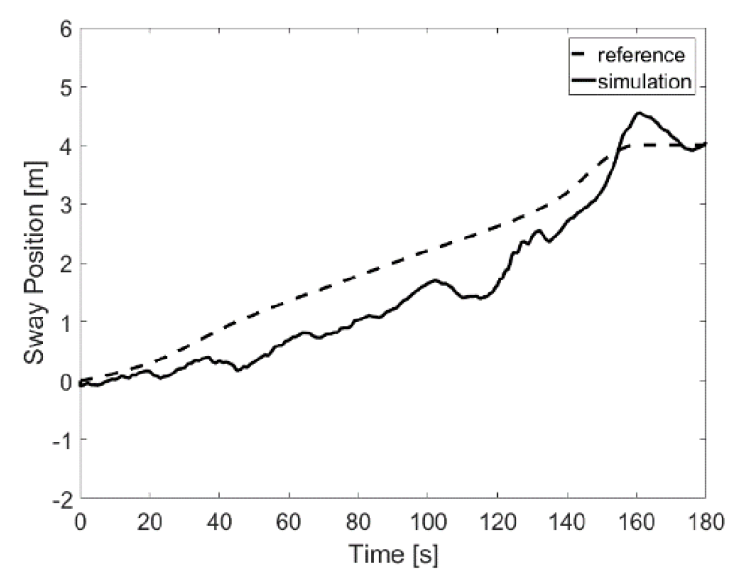

(b) Sway motion

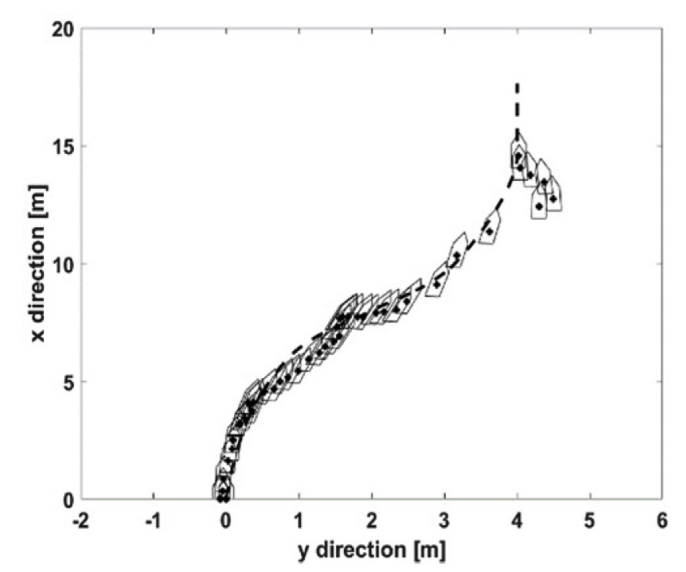

(d) Route tracking simulation result

Fig. 4 Ship motions while tracking the given target route in the uncontrolled mode

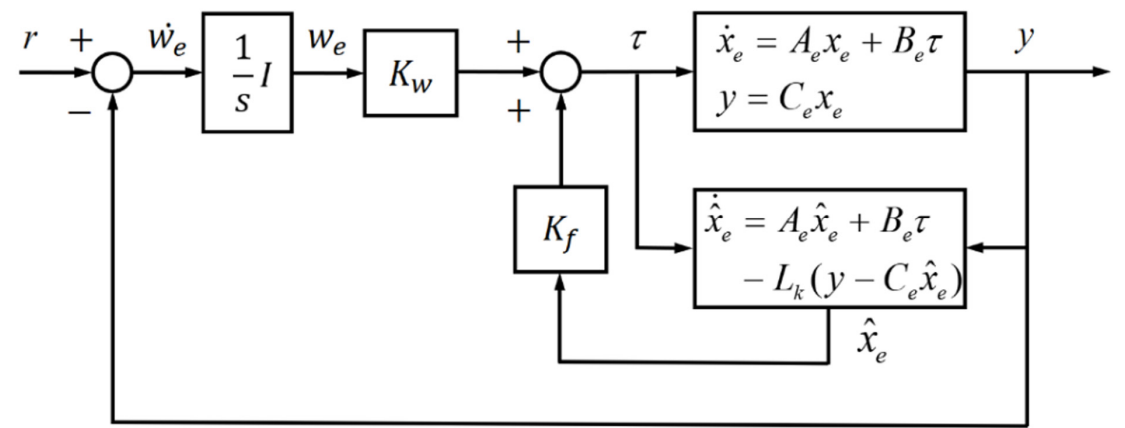

Fig. 5 Leader-following control system with state feedback control scheme

$$
\begin{aligned}
\dot{x}_{e} & =A_{e} x_{e}+B_{e} \tau+d w_{d} \\
& =A_{e} x_{e}+B_{e} K_{w} w_{e}-B_{e} K_{f} \hat{x}_{e}+d w_{d} \\
& =A_{e} x_{e}+B_{e} K_{w} w_{e}-B_{e} K_{f}\left(x_{e}-e_{x}\right)+d w_{d} \\
& =\left(A_{e}-B_{e} K_{f}\right) x_{e}+B_{e} K_{f} e_{x}+B_{e} K_{w} w_{e}+d w_{d}
\end{aligned}
$$

Thus, Eq. (10) - Eq. (19) can be written in matrix form as follows:

$$
\left[\begin{array}{c}
\dot{x}_{e} \\
\dot{e}_{x} \\
\dot{w}_{e}
\end{array}\right]=\left[\begin{array}{ccc}
A_{e}-B_{e} K_{f} & B_{e} K_{f} & B_{e} K_{w} \\
0 & A_{e}-L_{k} C_{e} & 0 \\
-C_{e} & 0 & 0
\end{array}\right]\left[\begin{array}{l}
x_{e} \\
e_{x} \\
w_{e}
\end{array}\right]+\left[\begin{array}{l}
d \\
d \\
0
\end{array}\right] w_{d}+\left[\begin{array}{l}
0 \\
0 \\
1
\end{array}\right] r
$$

where $K_{f}$ and $K_{w}$ are the linear optimal control gain matrices and $L_{k}$ is the gain matrix of the state estimator. In the control system design problem illustrated in Fig. 5 and Eq. (18), the gains $K_{f}, K_{w}, L_{k}$ should be calculated such that the feedback system is stable. Therefore, a candidate for stable observer gain is obtained by choosing $L_{k}$ such that the condition $\left(A_{e}-L_{e} C_{e}\right)<0$ is satisfied.

In general, the controller and observer gains are obtained by a numerical method, such as the linear matrix inequality (LMI) approach. In this study, the gains are calculated by the LMI optimization technique. 
In the result, the gains $K_{f}, K_{w}$ and $L_{k}$ are obtained as follows:

$$
K_{f}=\left[\begin{array}{ccccccc}
63.07 & 0 & 0 & 0.62 & 0 & 0.62 & 0 \\
0 & 123.45 & 0.84 & 0 & -0.62 & 0 & -0.41 \\
0 & 0.41 & 30.47 & 0 & 0 & 0 & 0 \\
& 76.20 & 0 & 88.22 & 0 & 0 \\
& 0 & 116.24 & 0 & 93.80 & 0.69 \\
& 0 & 0.10 & 0 & -0.21 & 79.62
\end{array}\right]
$$$$
K_{w}=\left[\begin{array}{ccc}
20.00 & 0 & 0 \\
0 & 19.99 & 0.10 \\
0 & -0.10 & 19.99
\end{array}\right]
$$$$
L_{k}=\left[\begin{array}{ccccc}
-0.13 & 0 & 0.17 & 0 & 0 \\
0 & -0.11 & 0 & 0.15 & -0.01 \\
0 & -0.01 & 0 & -0.04 & 0.10 \\
-0.55 & 0.59 & 0 & 0 & 0 \\
0 & -0.41 & 0 & 0.45 & -0.02 \\
0.70 & 0 & 0.15 & 0 & 0 \\
0 & 0.72 & 0 & 0.11 & -0.01 \\
0.23 & 0 & 0.12 & 0 & 0 \\
0 & 0.23 & 0 & 0.09 & -0.01 \\
0.15 & 0 & 0.74 & 0 & 0 \\
0 & 0.11 & 0 & 0.79 & -0.04 \\
0 & -0.01 & 0 & -0.04 & 0.46
\end{array}\right]
$$

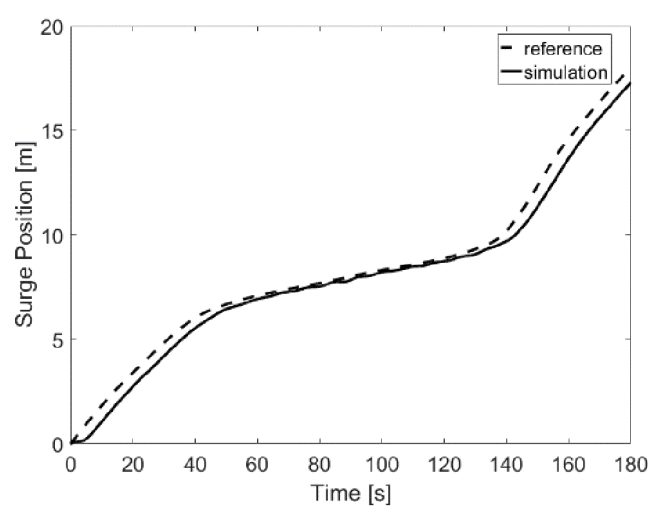

(a) Surge motion

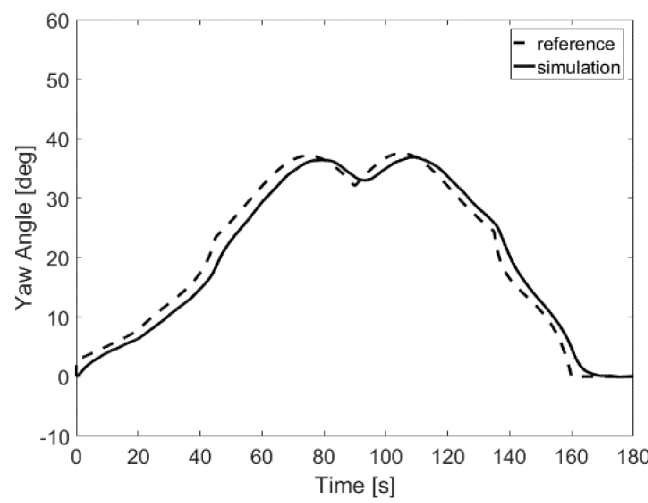

(c) Yaw motion

Fig. 6 Target route (dashed) and controlled response (solid)

\section{Simulation results}

This section presents and discusses the simulation results. For illustration purposes, the authors use the ship model given in Eq (15).

Here, the towed vessel will follow the target route that is made by the towing vessel. The target route is precisely generated by moving the position $\left(x_{0}(t), y_{0}(t)\right)$ in real-time. The position $\left(x_{0}(t), y_{0}(t)\right)$ is to be controlled in the real-application case. However, the towing vessel's control is not of interest in this study; it just works as the route generator for the towed vessel. Therefore, the target route is arbitrarily defined by the user.

To obtain the simulation results, the initial position is set as $(0.0$ $\mathrm{m}, 0.0 \mathrm{~m}, 0.0 \mathrm{rad})$ for $\left(x_{0}, y_{0}, \varphi_{0}\right)$. The vessel has to approach the final target position $(15.0 \mathrm{~m}, 4.0 \mathrm{~m}, \pi / 2 \mathrm{rad})$ by keeping system stability.

In the same manner of the uncontrolled case shown in Fig. 4, Fig. 6 shows the controlled responses and Fig. 7 represents the control actions of the three rudders. Figs. 6(a), 6(b), and 6(c) represent the surge, sway motion, and yaw angle of the towed vessel, respectively. In these figures, the solid line represents the target route (towing vessel motion), whereas the dashed line shows the towed vessel's motion.

Evidently, the controlled vessel can follow the target route stably

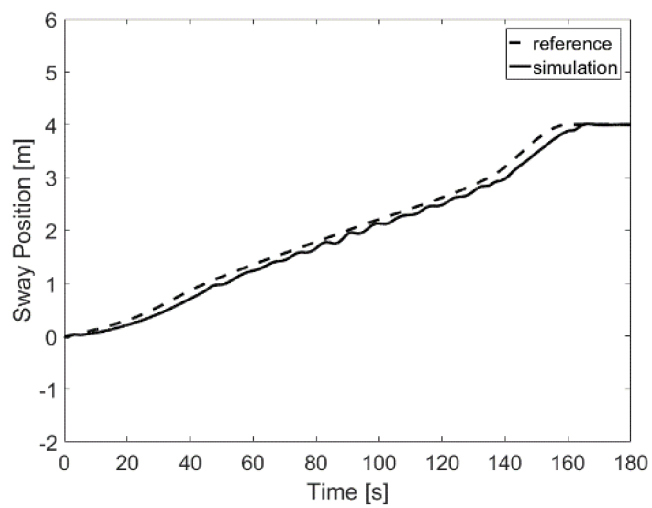

(b) Sway motion

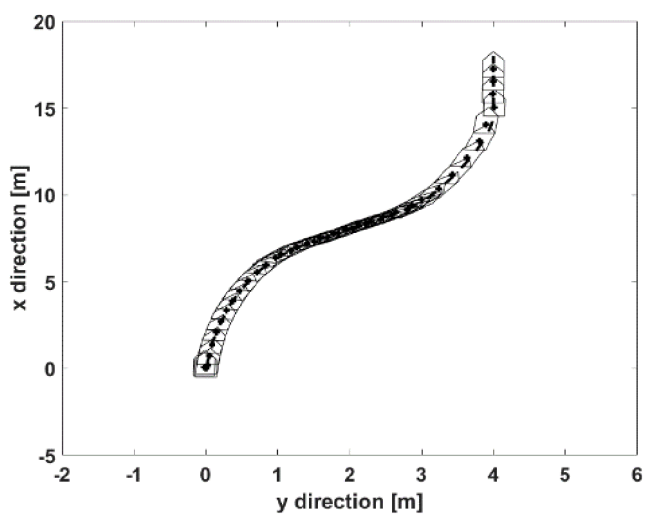

(d) Root tracking simulation result 


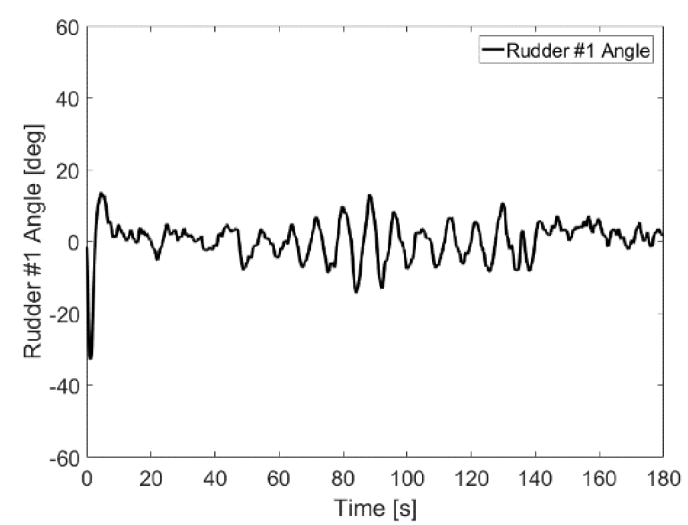

(a) Motion of rudder \#1

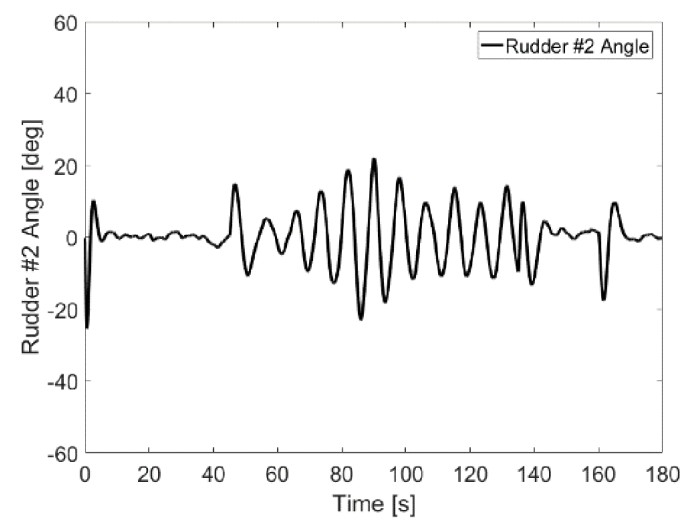

(b) Motion of rudder \#2

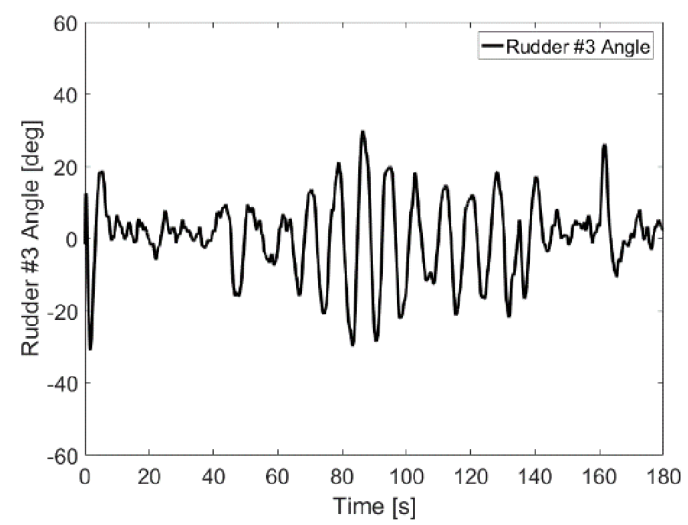

(c) Motion of rudder \#3

Fig. 7 Rudders control actions

and adequately.

By comparing the (d) of each figure that shows the moving trajectories, it is evident that the proposed control scheme works satisfactorily, and an excellent control performance is obtained.

\section{Conclusion}

In this study, the authors considered the control problem of a towed vessel without a power propulsion system and proposed a novel method to solve this critical issue. The controlled system consists of two vessels which are connected to each other by a rope, working as a leader-and-following system. On one hand, the towing vessel works as the leader and has the power propulsion system. On the other hand, the towed vessel called the follower is connected to the leader and does not contain any active system. Therefore, the safety in maneuvering is not preserved. If the vessel is exposed to harsh environmental conditions, collision may be inevitable. To overcome this limitation, the authors have designed a control mechanism. Notably, the rudders were newly installed on the towed vessel, such that the towed vessel can possess motion control ability. Using the proposed formulation, the system stability, control performance, and optimization problem are integrated into one step. The simulation results demonstrate the effectiveness of the proposed approach.
Moreover, this approach is applicable to the control of similar marine systems in various settings.

\section{Acknowledgment}

This work was supported by a Research Grant of Pukyong National University (2019 Year).

\section{References}

Bui, V.P., Jeong, J.S., Kim, Y.B., Kim, D.W., 2010. Optimal Control Design for Automatic Ship Berthing by Using Bow and Stern Thrusters. Journal of Ocean Engineering and Technology, 24(2), 10-17.

Bui, V.P., Kawai, H., Kim, Y.B., Lee, K.S., 2011. A Ship Berthing System Design with Four Tug Boats. Journal of Mechanical Science and Technology, 25(5), 1257-1264.https://doi.org/10. 1007/s12206-011-0215-4

Bui, V.P., Kim, Y.B., 2011. Development of Constrained Control Allocation for Ship Berthing by Using Autonomous Tugboats. International Journal of Control Automation and Systems, 9(6), 1203-1208. 10.1007/s12555-011-0622-4

Chingiz, H., Halil, E., Soken, S., Yenal, V., 2015. Linear Quadratic 
Regulator Controller Design. State Estimation and Control for Low-cost Unmanned Aerial Vehicles, 171-200. https://oi.org/ 10.1007/978-3-319-16417-5_10

Fossen, T.I., 2002. Marine Control System-Guidance, Navigation, Rigs and Underwater Vehicle. Marine Cybernetics, Trondheim, Norway.

Ji, H., Zhang, X., Ji, H., 2018. Research on Ship Borne UXB Antenna Servo System Based on LQG Controller. Proceedings of 3rd International Conference on Advances in Materials, Mechatronics and Civil Engineering, 162, 403-406. https://doi.org/10.2991/ icammce-18.2018.90.

Lee, D.J., Kim, J.K., Kim, B.S., 2000. Design of an Automatic Winch System for Small Fishing Vessel. Bulletin of Journal of the Korean Society for Fisheries and Technology, 36(3), 157-165.

Lopez, M.J., Rubio, F.R., 1992. LQG/LTR Control of Ship Steering Autopilots. Proceedings of the 1992 IEEE International Symposium on Intelligent Control, 447-450.

Tran, A.M.D., Ji, S.W., Kim, Y,B,, 2014. A Ship Berthing System Design by Cooperating with Tugboats and Dampers. Journal of Drive and Control, 11(3), 7-13. https://doi.org/10.7839/ ksfc.2014.11.3.007

Tran, A.M.D., Kim, Y.B., 2016. Dynamic Identification and Robust Control Performance Evaluation of Towing Rope under Rope
Length Variation. Journal of the Korean Power System Engineering, 20(2), 58-65. https://doi.org/10.9726/kspse.2016. 20.2.058

Tran, D.Q., Lee, D.H., Kim, T.W., Kim, Y.B., Park, H.C., 2018. A Study on Maneuvering Performance Improvement of a Towed Vessel without a Power Propulsion system: System Modeling. Journal of the Korean Society of Fisheries and Ocean Technology, 54(4), 343-352. https://doi.org/10.3796/KSFOT. 2018.54.4.343

Wondergem, M., Lefeber, E., Pettersen, K.Y., Nijmeijer, H., 2011. Output Feedback Tracking of Ships. IEEE Transactions on Control Systems Technology, 19(2), 442-448. https://doi.org/ 10.1109/TCST.2010.2045654

Yamato, H., Uetsuki, H., Koyama, T., 1990. Automatic Berthing by the Neural Controller. Proceedings of 9th Ship Control Systems Symposium, USA, 3, 183-201.

Zhang, Y., Hearn, G.E., Sen, P., 1997. A Multivariable Neural Controller for Automatic Ship Berthing. Journal of IEEE Control System Margazine, 17(4), 31-44. https://doi.org/10.1109/37. 608535

Zwierzewicz, Z., 1999. On the Ship Trajectory Tracking LQG Controller Design. Transactions on the Built Environment, 42, 399-406. https://doi.org/10.2495/MT990431 